\title{
THE MICROCIRCULATION OF CHOROIDAL AND CILIARY BODY MELANOMAS
}

\author{
ROBERT FOLBERG ${ }^{1,2}$, MARY MEHAFFEY ${ }^{1}$, LYNN M. GARDNER ${ }^{1}$, \\ MARGARET MEYER ${ }^{1}$, VOLKER RUMMELT ${ }^{3}$ and JACOB PE'ER ${ }^{4}$ \\ Iowa City, Iowa; Erlangen, Germany; and Jerusalem, Israel
}

\begin{abstract}
SUMMARY
The microcirculation of ciliary body and choroidal melanomas is remodelled into patterns. The presence of microvascular networks, composed of back-to-back loops that encircle microdomains of tumour, and parallel vessels with cross-linking, are associated with death from metastatic melanoma. The formation of these complex vascular patterns may result from reciprocal interactions between the tumour cell and the extracellular matrix, and pattern formation may reflect an invasive tumour cell phenotype. Ciliary body and choroidal melanomas are among the few forms of cancer treated before a pathologist assigns a grade to indicate whether tumour is likely to follow a benign or aggressive course. There is evidence to suggest that prognostically significant microcirculatory patterns may be detectable by non-invasive imaging techniques that may provide a substitute for biopsy to guide the clinical management of patients with these sight- and lifethreatening tumours.
\end{abstract}

\section{CILIARY BODY AND CHOROIDAL MELANOMAS: CONSIDERING BOTH CYTOLOGY AND ARCHITECTURE}

Since Callender's description of cell types in uveal melanoma, ${ }^{1}$ ophthalmic pathologists have been preoccupied with the relationship between the appearance of neoplastic melanocytes and the outcome of patients with melanomas of the iris, ciliary body and choroid. ${ }^{2-11}$ Studies describing cytological pleomorphism quantitatively by measuring the standard deviation of nucleolar area ${ }^{10,12-14}$ concentrated focus on the tumour cell even further.

From: Departments of ${ }^{1}$ Ophthalmology and Visual Sciences and ${ }^{2}$ Pathology, University of Iowa, Iowa City, Iowa, USA; ${ }^{3}$ Department of Ophthalmology, University of Erlangen-Nürnberg, Erlangen, Germany; and ${ }^{4}$ Department of Ophthalmology, Hadassah-Hebrew University, Jerusalem, Israel.

Correspondence to: Robert Folberg, University of Iowa, 100 Medical Research Center Room 233, Iowa City, IA 52242-1182. Fax: +1(319) 335-7193. e-mail: robert-folberg@uiowa.edu.
Tumour cells interact dynamically with the extracellular matrix and these reactions may be reciprocal, with tumour cells influencing the formation of the matrix and the matrix influencing tumour cell behaviour. $^{15,16}$ These progressive and reciprocal interactions are responsible for the generation of tumour stroma. ${ }^{17}$ To study the cytology of a neoplasm and ignore the tumour stroma is analogous to considering the wall of a building as a collection of bricks without acknowledging the contribution of the mortar.

In this discussion, attention is focused on the microcirculatory component of the stroma of ciliary body and choroidal melanomas.

\section{THE FORMATION OF PATTERNS IN CILIARY BODY AND CHOROIDAL MELANOMAS: ANGIOGENESIS AND VASCULAR REMODELLING}

Angiogenesis plays a particularly important role in the biology of uveal melanomas: choroidal and ciliary body melanomas can only disseminate haematogenously because there are no lymphatics within the eye. However, angiogenesis involves two processes: the production of new blood vessels and remodelling of the new vascular bed. ${ }^{18}$

Considerable attention has been focused on the prognostic significance of the production of new vessels in the metastatic process ${ }^{19,20}$ as pathologists have attempted to determine the relationship between the quantity of tumour vascularisation and outcome. In 1991, Weidner et al. ${ }^{21}$ reported a significant relationship between the quantity of microvessels in histological sections of breast cancer and subsequent metastasis. For each tumour, the zone of maximum vascular density was identified at low magnification, the number of discrete vessels was counted in a predefined area, and a threshold count that separated patients at low risk from those at high 
risk was established. High vascular density assessed from histological material has since been associated with a poor prognosis in some forms of cutaneous melanoma, ${ }^{22-24}$ non-small-cell carcinoma of the lung, ${ }^{25}$ prostatic ${ }^{26,27}$ and bladder cancer, ${ }^{28-30}$ nasopharyngeal cancer, ${ }^{31}$ and gliomas. ${ }^{32}$ The subject of vascular counts and prognosis was reviewed recently. ${ }^{33}$

Vessel counting from histological sections to establish prognosis does not hold for all forms of cancer. ${ }^{34}$ Carnochan et $a .^{24}$ discovered that the density of tumour vessels did not correlate well with the outcome for certain cutaneous melanomas (a more recent study of cutaneous melanoma showed no relationship between vascular counts and outcome ${ }^{35}$ ), and suggested that 'assessment of other features of the tumour vasculature may provide a useful complement to simple morphometry'. Recently, Page and Jensen, ${ }^{36}$ commenting on the failure of two teams of investigators to confirm the prognostic significance of the vessel-counting in breast cancer, ${ }^{37,38}$ stated that 'intratumoral angiogenesis may be related more to continual remodelling and migration of vessels than to continual production of new vessels'.

\section{MICROCIRCULATORY PATTERNS OF CHOROIDAL AND CILIARY BODY MELANOMAS}

Tissue remodelling generates zones of regional specification or patterns. ${ }^{39}$ The remodelling of the microcirculation of ciliary body and choroidal melanomas into patterns was demonstrated in histological sections. ${ }^{40,41}$ In addition to normal vessels incorporated into the stroma of these tumours and focal avascular zones, these tumours contain straight vessels, parallel straight vessels, parallel vessels that cross-link, vascular arcs (incomplete loops), arcs with branching, closed vascular loops that encircle small clusters of tumour cells, and microvascular networks composed of back-to-back loops. ${ }^{40}$ The detection of these patterns in histological sections is highly reproducible between observers. ${ }^{41.42}$ These histological patterns are illustrated in Fig. 1.

\section{MICROCIRCULATORY ARCHITECTURE AND METASTASIS FROM CHOROIDAL AND CILIARY BODY MELANOMAS}

In a preliminary matched-pair case-control study of 40 patients with choroidal or ciliary body melanoma, the presence of vascular loops was associated with death from metastatic melanoma, ${ }^{40}$ a finding con-

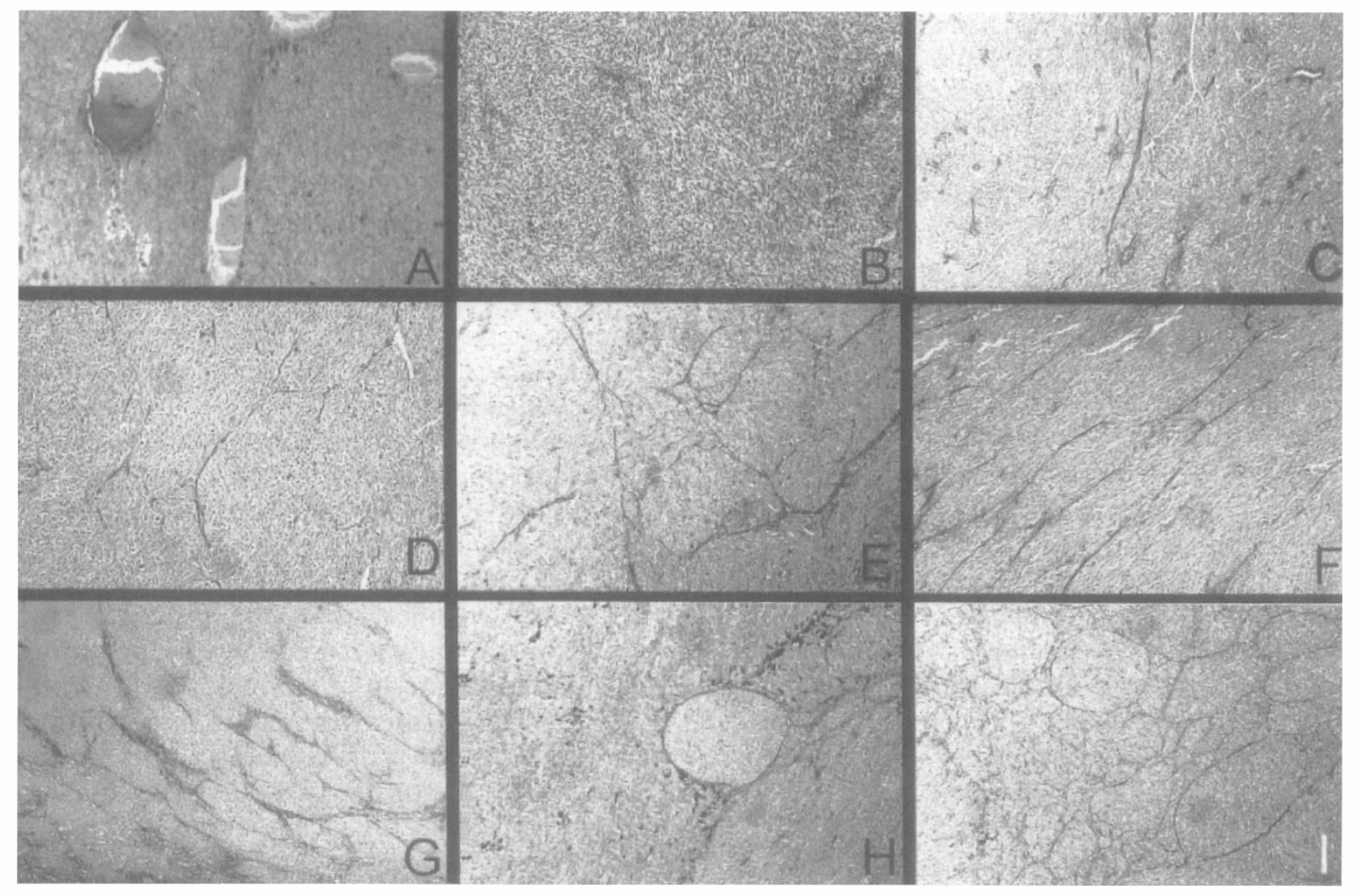

Fig. 1. Microcirculatory patterns. (A) Tumour surrounds normal vessels. (B) Avascular zone. (C) Straight vessels. (D) Arcs. $(E)$ Incomplete loops or arcs with branching. $(F)$ Parallel vessels with one focus of cross-linking in the lower left corner. $(G)$ Parallel vessels with cross-linking. $(H) A$ vascular loop surrounds a focus of relatively amelanotic tumour just to the right of centre. (I) Networks composed of back-to-back vascular loops. Periodic acid-Schiff (PAS) stain without haematoxylin counterstaining, photographed through a green filter; original magnification $\times 25$ for all figures. 
firmed recently by Sakamoto et al. ${ }^{42}$ In a larger series of 234 patients, Kaplan-Meier survival curves generated from deaths due to metastatic melanoma indicated that at 10-year follow-up the survival of patients whose tumour lacked the vascular patterns of parallel vessels with cross-linking, loops and networks was significantly better $(91.7 \%, 91.1 \%$ and $88.3 \%$, respectively) than for patients whose tumours contained these patterns $(56.9 \%, 55.4 \%$ and $50.7 \% ; p=0.0001$ for all comparisons, $n=234)$. A Cox proportional hazards model was generated that permitted inclusion of the conventional prognostic factors (including the largest tumour dimension in contact with the sclera, cell type, tumour infiltrating lymphocytes, mitotic figures, gender, and location of the tumour within the eye) and the presence or absence of each of the nine microcirculatory patterns. The most important variable was the network pattern (chi-square $=40.84 ; p=0.0001$ ). Other significant factors in the model include (in descending order of importance) largest tumour dimension, mitoses, parallel with cross-linking vascular patterns, age, the presence of tumour-infiltrating lymphocytes, and male gender. ${ }^{41}$ It was not surprising that loops did not appear in the final Cox model, because networks, the most significant variable in this model, are composed of back-to-back loops. ${ }^{40}$

\section{MICROCIRCULATORY PATTERNS AS A MARKER OF TUMOUR PROGRESSION IN CHOROIDAL AND CILIARY BODY MELANOMAS}

There are abundant descriptions of the precursors of cutaneous melanoma, ${ }^{43}$ but ophthalmic pathologists traditionally recognise only naevi (including the melanocytoma naevus variant) and melanomas. ${ }^{43}$ The existence of uveal melanocytic hyperplasia was advanced as a hypothesis, ${ }^{44}$ but has never been demonstrated clinically or histologically in humans. There is no mention in the ophthalmic pathology literature of 'atypical melanocytic hyperplasia' in the choroidal, ciliary body or iris. ${ }^{45}$

To determine whether microcirculatory patterns could assist in refining the classification of uveal melanocytic neoplasms, the microcirculation architecture of choroidal and ciliary body naevi was examined. Tissue blocks from 23 naevi of the ciliary body or choroid were identified from the laboratories of the University of Iowa and the University of Erlangen-Nürnberg. A naevus was defined by the criteria of Naumann et al. ${ }^{46,47}$ and excluded lesions that contained any spindle B or epithelioid cells. Rummelt et al. ${ }^{48}$ discovered that choroidal and ciliary body naevi contain only four vascular patterns: normal vessels, avascular zones, straight vessels, and parallel vessels that do not cross-link. None of the naevi contained parallel vessels with cross- linking, arcs, arcs with branching, vascular loops or networks.

A study was designed to test the hypothesis that melanomas could be classified into prognostic groups on the basis of microcirculation architecture patterns. $^{48}$ Of the 234 melanomas in this dataset, 49 contained a naevus-like microcirculation and 185 contained vascular patterns not found in naevi. Melanomas with a naevus-like microcirculation tend to develop in the choroid posterior to the equator $(p=0.0007)$ and tend to be smaller $(p=0.0001)$ than melanomas lacking a naevus-like microcirculation. The mortality from cancer for patients whose tumours lack naevus-like microcirculation is $32.4 \%$ compared with tumours with a naevus-like microcirculation $(14.3 \%, p=0.012)$. Kaplan-Meier curves plotting the survival of patients whose melanomas had a naevus-like microcirculation versus those whose tumours contained non-naevus patterns revealed that at 15 years' follow-up the survival of patients with naevus-like melanomas is $84.8 \%$ versus $60.4 \%$ for patients whose tumours lacked a naevuslike microcirculation $(p=0.0007)$. In addition, the median interval between enucleation and death from metastatic melanoma for patients whose tumour had a naevus-like microcirculation is significantly longer (median 6.4 years; range 4.5-16.2 years) than for patients whose tumours featured microcirculatory patterns other than those seen in naevi (median 3.6 years; range $0.5-18$ years; $p=0.018$ ).

These findings suggested that there are at least three types of melanocytic lesions that develop in the choroid and ciliary body: naevi (which lack the capacity for metastasis and are entirely benign), melanomas with vascular networks (which are strongly associated with metastasis), and melanomas with a naevus-like microcirculation architecture (which have only a limited capacity for metastasis and which tend to have a prolonged survival to death from metastatic melanoma if metastases do develop). The microcirculation architecture, therefore, can be used to define steps in the pathway of tumour progression in choroidal and ciliary body melanoma. $^{48}$

\section{THE COMPOSITION OF MICROCIRCULATORY PATTERNS}

Microvascular networks are not unique to uveal melanomas and have been described in a variety of tissue types and tumours. ${ }^{49-56}$ The appearance of a microvascular network in tissue sections should not be interpreted, therefore, as an implausible event. Indeed, the presence of a PAS-positive 'chickenwire' microcirculation is a histological characteristic of myxoid liposarcomas. ${ }^{57}$

The microcirculatory patterns of uveal melanoma were first demonstrated by a modification of the PAS 
stain (without haematoxylin counterstaining). The magenta colour of the patterns could be augmented by inserting a green filter into the light path of the microscope to turn the appearance of these patterns black and thus highlight them for observation and photomicroscopy. ${ }^{40}$ Not every structure that is PASpositive in these tumours is part of the microcirculatory system, and pathologists who used this method were cautioned to avoid interpreting all PAS-positive structures as microcirculatory. ${ }^{40,41}$

It is relatively difficult to bleach entire tumour cross-sections that have been stained to demonstrate endothelial-specific markers with immunohistochemical techniques without losing fragments of tissue (especially at the periphery) or inducing tissue folds. The loss of tumour tissue or the presence of artefacts introduced during staining may interfere significantly with the detection of patterns. If one attempts to bleach sections before applying immunohistochemistry, there is a risk of losing antigenic binding sites. With the modified PAS stain, the microcirculation is demonstrated even after removal of melanin from highly pigmented lesions by routine permanganate bleaching. 40

The claim that the modified PAS stain is an accurate approximation of the microcirculation ${ }^{40}$ is based upon four lines of evidence: $(a)$ networks have been traced in serial histological sections to vortex veins and the choriocapillaris (Fig. 2); (b) correlations have been established between PAS-positive patterns and microcirculatory patterns demonstrated by Ulex europaeus agglutinin $\mathrm{I}^{40}$ by laser scanning confocal microscopy; (c) three-dimensional reconstructions of these patterns by computer-assisted laser scanning confocal microscopy confirm convincingly the vascular nature of these patterns ${ }^{58}$ (Fig. 3); and $(d)$ transmission electron microscopy has con-

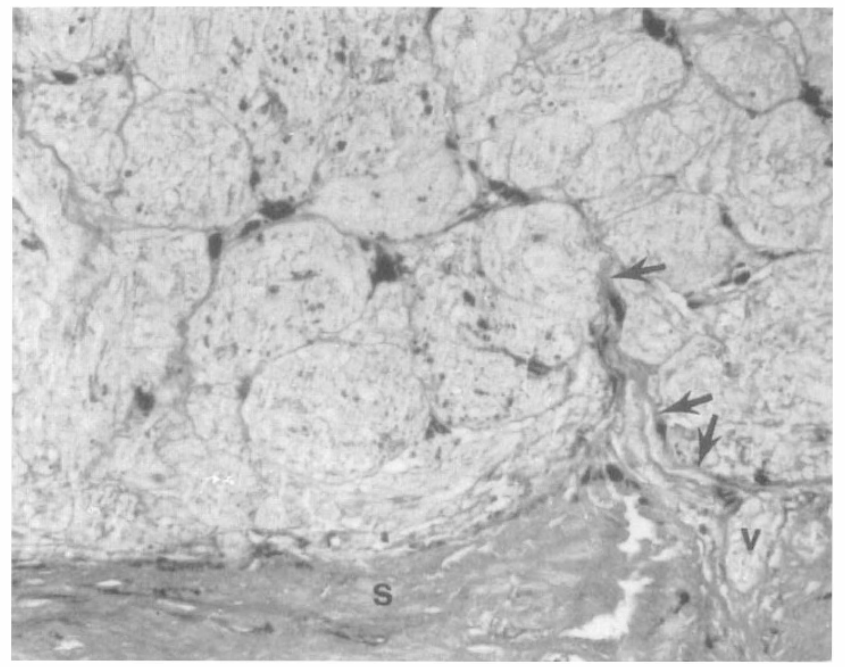

Fig. 2. Microvascular networks are traced (arrows) to the vortex vein $(v)$ in the lower right corner (s, sclera). PAS without haematoxylin counterstaining; original magnification $\times 50$.

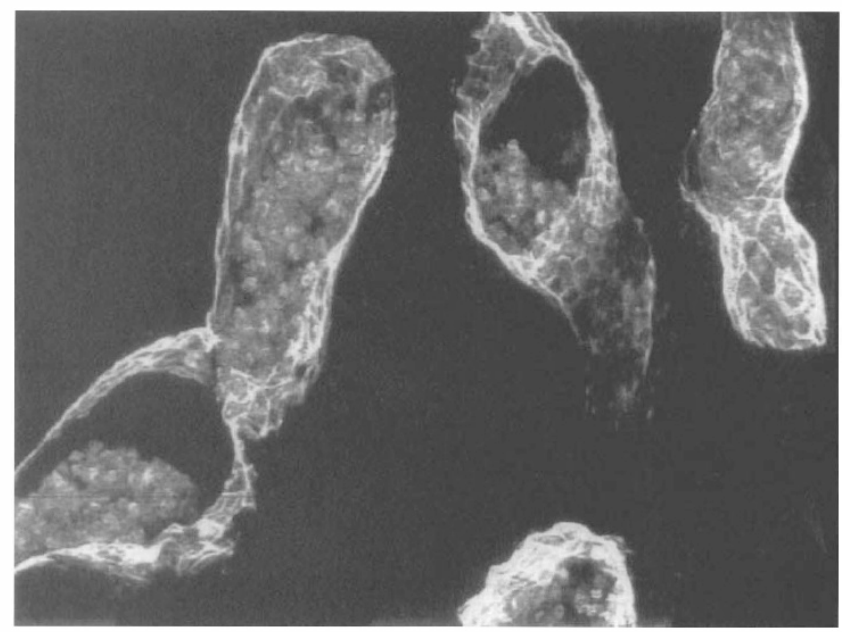

(a)

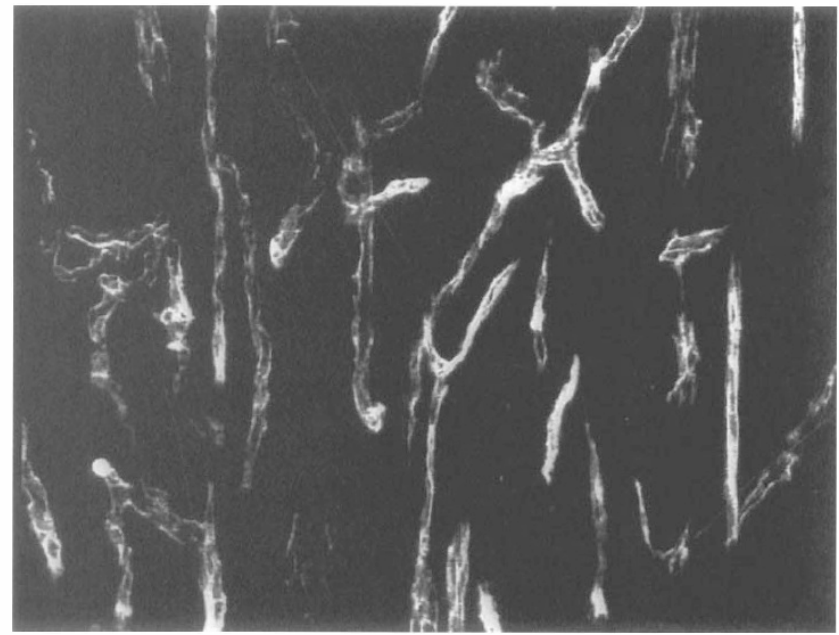

(b)

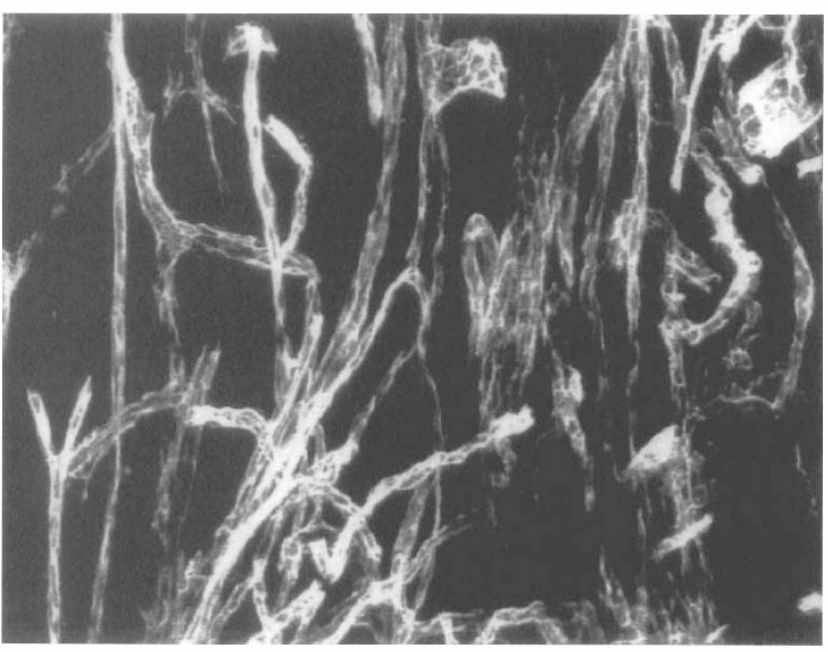

(c)

Fig. 3. Three-dimensional reconstructions by laser-scanning confocal microscopy. (a) Red blood cells are identified in the cut edges of gaping normal vessels. (b) Parallel vessels with a focus of cross-linking (centre). (c) Note the back-to-back loops just left of centre and at the bottom. Ulex europaeus agglutinin I-FITC; original magnification $\times 20(a)$ and $\times 10(b, c)$. 
firmed the vascular nature of these structures, demonstrating thin-walled vessels often containing red blood cells in a rouleaux formation. ${ }^{40,48}$

Additional ultrastructural studies of the microcirculation revealed interesting differences between normal choroidal microvessels, the microcirculation in naevi, and melanomas with and without a naevuslike microcirculation. ${ }^{48}$ For example, there was a significant difference $(p=0.0008)$ in the thickness of the microvascular basement membranes in the normal choroid (median thickness $0.47 \mu \mathrm{m}$ ), naevi (median thickness $0.49 \mu \mathrm{m}$ ) and melanomas with a naevus-like microcirculation (median thickness $1.15 \mu \mathrm{m})$. In melanomas without a naevus-like microcirculation, there was a tendency for the microvascular basement membranes to be thicker than in vessels in the other three groups. Qualitatively, the basement membrane of vessels in normal eyes, naevi, and melanomas with naevus-like vascular patterns had no evidence of fragmentation, excessive collagen or a multilaminar construction. By comparison the microcirculation of melanomas without a naevus-like microcirculation featured multilaminar basement membrane, increased amounts of vascular-associated collagen, and basement membrane fragmentation. Interendothelial junctions were preserved in normal eyes, naevi, and melanomas with naevus-like microcirculatory patterns, but were absent in vessels in melanomas lacking naevus-like vascular patterns.

These ultrastructural findings are important for two reasons: $(a)$ vascular basement membranes in ciliary body and choroidal melanomas may be thickened and fragmented without previous exposure to radiation (these changes were attributed previously to a radiation effect ${ }^{59-63}$ ); and (b) alterations in the basement membrane and loss of endothelial cell junctions suggest a physiological breakdown in the blood-tumour barrier. ${ }^{64}$ Recently, it was shown that vessels in choroidal naevi did not leak indocyanine green while the vessels of choroidal melanomas were leaky. ${ }^{65}$ Disruption in the bloodtumour barrier of melanomas might facilitate some forms of perfusion-based therapies. ${ }^{66}$

Despite the considerable evidence that the prognostic patterns illustrated in Fig. 1 by PAS staining without haematoxylin counterstaining are microvascular, a team of investigators recently concluded that the microcirculatory nature of these prognostic patterns was in question because paraffin sections of melanomas stained to demonstrate factor VIII failed to demonstrate networks. ${ }^{67}$ Factor VIII is known to be a relatively insensitive marker for immature endothelium of the type seen in an angiogenic response in tumours (antigen expression in microcirculatory beds may be related to the relative maturity of the endothelium; ${ }^{68,69}$ Fig. 4).

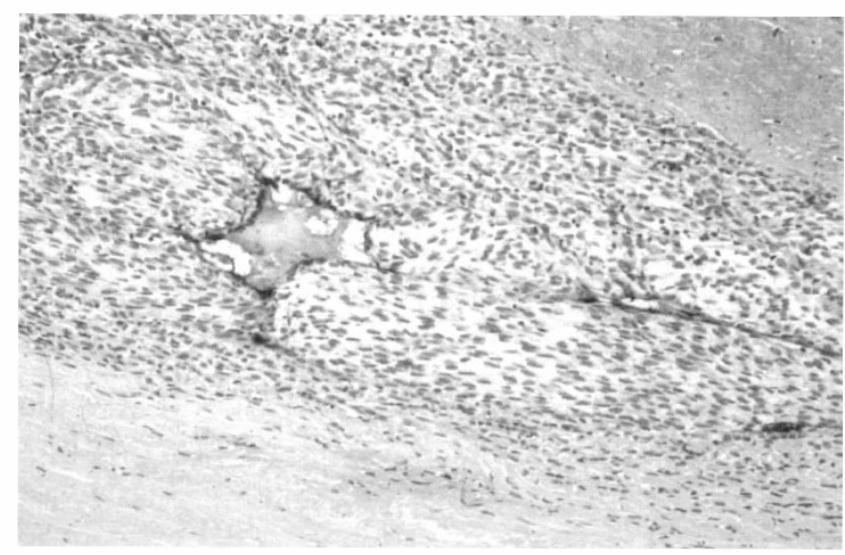

(a)

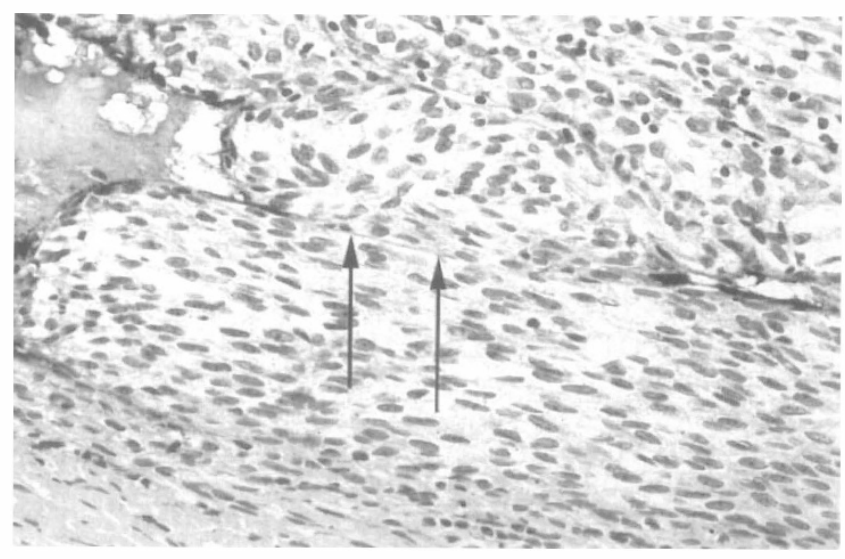

(b)

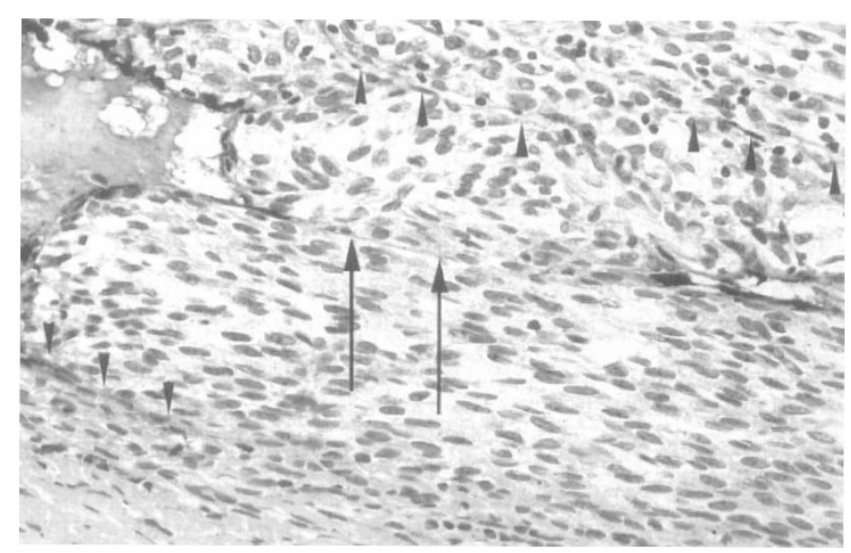

(c)

Fig. 4. Demonstration of microcirculation using von Willebrand factor (factor VIII). (a) Factor VIII appears to demonstrate two separate vessels at this magnification. (b) At higher magnification a thin-walled vessel continues from the larger vessel (long arrows) on the left but is not stained with factor VIII. (c) Same photomicrograph as (b), but arrowheads now call attention to other small vessels that are incompletely stained by factor VIII. Factor VIII-diaminobenzidine-haematoxylin; original magnification $\times 25$ (a) and $\times 100(b, c)$. 


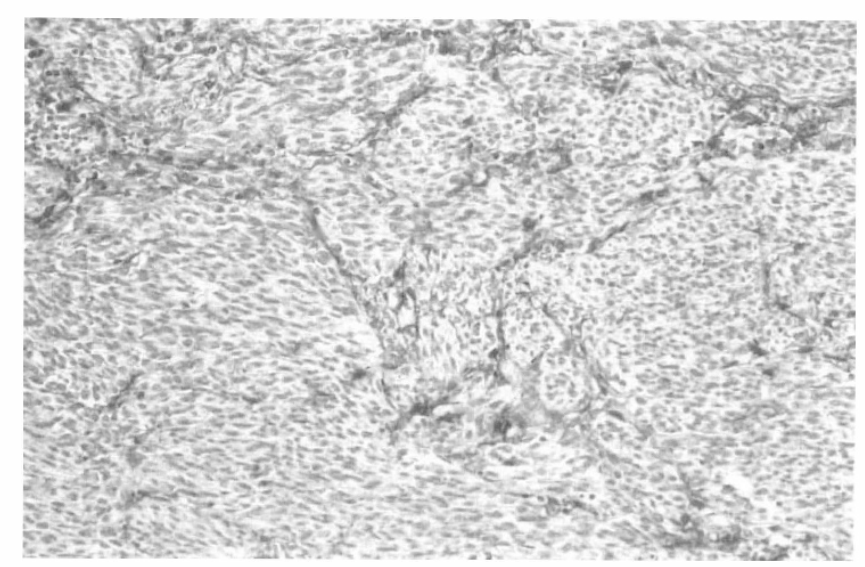

Fig. 5. Microvascular networks are identified with antibody to CD31. CD31-diaminobenzidine-haematoxylin; original magnification $\times 25$.

With more sensitive markers for endothelium, it is indeed possible to demonstrate microvascular loops, networks, and parallel vessels with cross-linking in tissue sections of choroidal and ciliary body melanomas (Fig. 5).

\section{CELL TYPE, PROGNOSIS AND MICROCIRCULATORY PATTERNS}

Cell type, long considered to be of paramount prognostic importance, ${ }^{1-11}$ does not appear in Cox proportional hazards models once microvascular patterns are permitted to enter the models. ${ }^{41}$ The relative insignificance of cell type as regards prognosis was confirmed subsequently by Mooy et al..$^{70}$ Even cytomorphometric measurements such as the mean of the ten largest nucleoli (MTLN) ${ }^{14.71}$ do not enter Cox models when vascular patterns are permitted to enter the model, ${ }^{72}$ and recently Coleman et al. ${ }^{73}$ confirmed the finding that MTLN may not be a significant prognostic variable in ciliary body and choroidal melanomas.

Because cell type does not appear in a Cox proportional hazards models does not mean that that cell type is not important in the phenomena of invasion and metastasis and in complex microvascular remodelling that results in the formation of networks: the presence of epithelioid cells is associated with the presence of networks, and the absence of epithelioid cells is associated with avascular zones. ${ }^{40}$

To understand the relationships between cytology, microvascular pattern formation, and invasion and metastasis, it is important to consider the mechanisms by which microvascular patterns form in ciliary body and choroidal melanomas.

\section{THE MECHANISMS OF MICROVASCULAR PATTERN FORMATION IN CHOROIDAL AND CILIARY BODY MELANOMAS}

Recently, type VI collagen and hyaluronan were detected around small blood vessels in the micro- circulation of choroidal and ciliary body melanomas and surrounding nests of cells separate from the microcirculatory bed. ${ }^{74}$ Type VI collagen and hyaluronan both stain positive with PAS stain; type I collagen is not PAS-positive. ${ }^{75,76}$ These observations may help to explain why it is possible to demonstrate microcirculatory patterns in routine sections with the PAS stain. ${ }^{40}$

Type VI collagen plays an important role in tissue remodelling, ${ }^{77}$ including the generation of tissue patterns and microvascular networks. ${ }^{78}$ Type VI collagen is distributed normally in the subendothelial compartment, ${ }^{79-81}$ but unlike type I collagen which is normally present in the stoma of the choroid, type VI collagen is normally present in low levels around the choriocapillaris and not present in the choroidal stroma. ${ }^{82}$

The mere presence of type VI collagen in the remodelled microcirculation of ciliary body and choroidal melanomas does not explain the association between the formation of microvascular networks and metastasis. In cultures of eight ciliary body or choroidal melanomas, thin and plump spindled cells (analogous to spindle A and B cells) and epithelioid cells were identified. ${ }^{74}$ Invasion assays into type I collagen gels were performed with all eight cell lines. Epithelioid cells and plump spindle cells invaded into type I collagen gels but the thin spindle cells did not invade and remained on the gel surface. Thus, cells that roughly match the Callender spindle B and epithelioid types were shown to be invasive in vitro, in contrast to spindle A cells which were not invasive in this assay.

Two lines of evidence suggested that the melanoma cells themselves are capable of synthesising type VI collagen: the direct demonstration of staining for type VI collagen in cultured melanoma cells and in tissue section, and the presence of type VI collagen mRNA as determined by reverse transcriptase-PCR. ${ }^{74}$ There was no evidence of type VI collagen production by thin spindle cells.

Tumour cells that had an invasive phenotype in vitro (spindle $\mathrm{B}$ and epithelioid cells) were the cell types capable of producing type VI collagen. Type VI collagen is thought to contribute to pattern formation and remodelling through the formation of scaffolds into which vessels grow. ${ }^{83}$ Therefore, the ability of tumour cells that have invasive characteristics to produce an element of the extracellular matrix associated with vascular remodelling (type VI collagen) may help to explain the association between the appearance of microvascular networks in tissue sections and the development of metastases.

Another line of investigation may shed light on the events that trigger microvascular pattern formation. In many studies, tumours involving the ciliary body have a worse prognosis than those located entirely in 
the choroid. ${ }^{6,7.84}$ However, in the multivariate Cox model including microcirculatory patterns, tumour location within the eye did not appear as an independent variable. ${ }^{41}$ It was discovered subsequently that microvascular networks tend to develop in the ciliary body relative to the choroid. ${ }^{85}$ This observation is important because deletion of chromosome 3 may be characteristic of ciliary body melanomas ${ }^{86}$ and has been associated with their aggressive behaviour. ${ }^{86.87}$ If the aggressive behaviour of melanomas with ciliary body involvement is related to deletion of chromosome 3 , if ciliary body tumours develop vascular networks preferentially, 85 and the presence of vascular networks has the strongest association with mortality due to melanoma of all other variables studied, ${ }^{40,41}$ then deletion of chromosome 3 may be related to the development of vascular networks.

\section{ADDRESSING A PROBLEM IN THE MANAGEMENT OF PATIENTS WITH CHOROIDAL OR CILIARY BODY MELANOMAS}

Understanding the development of tumour stroma in ciliary body and choroidal melanomas is more than a theoretical exercise. Ciliary body and choroidal melanomas are among the few forms of cancer treated before a pathologist assigns a grade to indicate whether tumour is likely to follow a benign or aggressive course. Although pathologists may contribute significant prognostic information after the eye has been removed, the only prognostic information available to ophthalmologists at the time of clinical diagnosis is based on the tumour size $e^{84}$ and the detection of extraocular extension by conventional ultrasonography or magnetic resonance imaging. Unfortunately, when choosing between enucleation and alternative vision-sparing treatments for their patients, ophthalmologists cannot use information from a histological examination of an incisional biopsy, a procedure that would be likely to disturb vision.

Ophthalmologists have tried to detect the cytological composition of the tumour clinically as a means of obtaining prognostic information that could guide management. Fine-needle aspiration biopsy separates uveal melanomas accurately from conditions that simulate these tumours clinically (e.g. metastases),${ }^{88}$ but its use as a prognostic tool is limited in at least four ways: $(a)$ There is a risk of sampling error when determining cell type: the needle track from a fine-needle aspiration biopsy was traced histologically on an enucleation specimen and was localised to a zone of spindle A and B melanoma cells, missing a pocket of adjacent epithelioid cells entirely. ${ }^{89}(b)$ There are no associations between cytomorphometric measurements on fine-needle aspiration biopsy samples and those from tissue sections of enucleated eyes. ${ }^{89.90}$ (c) Cell type may not provide the most important prognostic information currently available from the examination of tumour tissue: in Cox regression models that permit the entry of microvascular patterns as well as conventional prognostic features such as cell type, the tumour characteristic most strongly associated with metastasis is the network microcirculatory pattern; cell type did not even appear as an independent variable. ${ }^{48,72,85}(d)$ Fine-needle aspiration biopsy is invasive; it would be preferable to develop a noninvasive test to determine the patient's prognosis.

In designing a non-invasive substitute for biopsy, it would be reasonable to exploit not only the cytology of the tumour but any prognostic information that might be embedded in the tumour stroma, such as microvascular patterns. There have been two major approaches to detecting prognostically significant microcirculatory patterns clinically: indocyanine green angiography augmented by confocal ophthalmoscopy, ${ }^{91}$ and ultrasound power spectrum analysis. ${ }^{92}$

Indocyanine green angiography augmented by confocal ophthalmoscopy ${ }^{91}$ utilises a dye that is visible to a certain extent through melanin and the presence of a confocal system permits tomographic 'cuts' through the tumour, so microcirculatory patterns should be visible theoretically if they are within the resolution of the apparatus. Recently, Schneider et al. ${ }^{93}$ employed such a system to image the microcirculation of posterior choroidal melanomas and demonstrated parallel vessels with crosslinking at the periphery of a tumour. There may be three limitations to this promising new imaging technique: $(a)$ only tumours directly in the posterior pole can be imaged, $(b)$ in thick tumours it is not known whether the tumour adjacent to the sclera can be imaged, and $(c)$ it is not known whether the small, thin-walled vessels of prognostically significant microcirculatory patterns are beyond the resolution of the imaging equipment.

Ultrasound power spectrum analysis can be applied to patients with ciliary body or choroidal melanomas and is independent of the degree of pigmentation or thickness of the tumour. This specialised technique of ultrasound spectrum analysis of digitally recorded echoes returned from a tissue region provides statistical measures that are related to small spatial fluctuations in acoustic impedance. ${ }^{92}$ These measures can be used to derive physically relevant characteristics such as the mean size of tissue areas that backscatter ultrasound, and the acoustic concentration. ${ }^{92}$ In 1990, Coleman et al. ${ }^{94}$ suggested that these scatterer patterns might be 'associated with tumour micro-regions such as intervascular nests of cells, rather than directly with the 
individual size of cells'. This clinical observation suggested that the stroma of choroidal and ciliary body melanomas might be organised into regions or patterns. The following year, Coleman et al. ${ }^{95}$ showed that these 'cell distribution patterns' detected by ultrasound power spectrum analysis were related to outcome in patients with choroidal and ciliary body melanomas.

It was particularly interesting that the dimensions of tumour outlined histologically by closed vascular loops measured from digitised laser scanning confocal microscopy images (width 14-116 $\mu \mathrm{m}$, median $43 \mu \mathrm{m}$; length $30-157 \mu \mathrm{m}$, median $70 \mu \mathrm{m}^{40}$ ) corresponded well with acoustic scatterer patterns of prognostic importance reported by Coleman et al. $\left(40-110 \mu \mathrm{m}\right.$ in diameter). ${ }^{96}$ The correspondence between acoustic scatterer sizes and the size of tumour micro-regions outlined histologically by the closed vascular loops in networks suggested that ultrasound spectrum analysis might be capable of detecting this prognostically significant feature of ciliary body and choroidal melanomas clinically, thus forming the basis of a non-invasive substitute for biopsy.

Five patients were examined by ultrasound spectrum analysis before enucleation for ciliary body or choroidal melanoma. ${ }^{97}$ Three-dimensional ultrasound images that depict the size and relative concentration of scattering elements within ranges of $50-120 \mu \mathrm{m}$ were compared with histological sections stained with PAS without haematoxylin ${ }^{40}$ to permit the identification of microvascular patterns. Vascular networks were identified histologically in three tumours. The predominant ultrasound features seen in the regions of the histologically identified networks were clusters of scatterers in the range 50-80 $\mu \mathrm{m}$. In the two cases without networks, lower range scatterers dominated the tumour volume. This pilot study suggested that ultrasound spectrum analysis parameters used to subclassify uveal melanoma may have a biophysical basis related to patterns of tumour microcirculation. Additional studies are being conducted in a prospective fashion to correlate this imaging technique with histological pattern classification.

If ophthalmologists could determine the biological grade of a ciliary body or choroidal melanoma clinically by a non-invasive study, how would this information be used? A patient at high risk for metastasis in the absence of detectable elevations of liver enzymes or abnormal liver scans may benefit from adjuvant chemotherapy to reduce any small foci of extraocular tumour burden. ${ }^{98-100}$ What would be the value of knowing that a patient with a ciliary body or choroidal melanoma was at low risk for metastasis? The natural history of a histological lowgrade choroidal or ciliary body melanoma is unknown because its course has been interrupted by enucleation. Would a patient classified clinically as having a lesion at low risk for metastasis be observed and monitored by repeated non-invasive 'biopsies' or would the lesion be treated? There are no answers to these questions now, but the availability of a non-invasive substitute for biopsy would make it possible in future to conduct future prospective clinical studies to investigate these problems. It is not even possible to address these issues without an accurate method of grading these tumours clinically.

Would treatment of the primary tumour be different if it were classified clinically at low risk instead of higher risk? The development of a clinical prognostic test based on properties of the microcirculation may contribute to improving existing vision-sparing treatments: radiation therapy may target the tumour vasculature, ${ }^{61,62,101-104}$ and the response to hyperthermia may be related to tumour vascularity. ${ }^{105-111} \mathrm{~A}$ better understanding of the microcirculation of these tumours may contribute significantly to the development of new therapeutic strategies. For example, it is known that vascular networks establish a microenvironment of oxygen and nutrients within a tumour and that focal avascular zones produce local tissue hypoxia. ${ }^{52}$ Therefore, it may be possible to design new visionsparing treatments for the primary tumour with emerging strategies such as hypoxia-activated chemotherapeutic agents and other novel anti-angiogenesis therapies. ${ }^{112}$

\section{CONCLUSIONS}

The investigations summarised above represent an attempt to balance the ledger in describing the pathology of choroidal and ciliary body melanomas. The pathology of the tumour stroma may contribute significant prognostic information that may be translated into the improvement of clinical classification and management of patients with choroidal and ciliary body melanomas - tumours that threaten not only to shorten the lifespan of the patient but to compromise vision.

The study of tumour cell-matrix and stromal interactions in choroidal and ciliary body melanomas has implications that extend far beyond the boundaries of the practice of clinical ophthalmology. ${ }^{45}$ Uveal melanomas represent a model system for the pure haematogenous dissemination of tumours, because there are no lymphatics within the eye. Moreover, the noted tendency for these tumours to spread preferentially to the liver makes choroidal and ciliary body melanomas paradigms for the study of human organ-specific metastasis. Research in ophthalmic oncology may therefore contribute sig- 
nificantly to an overall understanding of the mechanisms of invasion and metastasis.

This work was supported by grant 10457 from the National Institutes of Health, Bethesda, Maryland, and in part from an unrestricted grant to the University of Iowa by Research to Prevent Blindness, Inc., New York, New York.

Key words: Melanoma, Metastasis, Angiogenesis, Prognosis, Type VI collagen, Ultrasound, Indocyanine green angiography, Extracellular matrix.

\section{REFERENCES}

1. Callender GR. Malignant melanotic tumors of the eye: a study of histologic types in 111 cases. Trans Am Acad Ophthalmol Otolaryngol 1931;36:131-42.

2. Wilder HC, Callender GR. Malignant melanoma of the choroid: further studies on prognosis by histologic type and fiber content. Am J Ophthalmol 1939; 22:851-5.

3. Callender GR, Wilder HC, Ash JE. Five hundred malignant melanomas of the choroid and ciliary body followed five years or longer. Trans Am Acad Ophthalmol Otolaryngol 1942;46:223-30.

4. Paul EV, Parnell, BL, Fraker M. Prognosis of malignant melanomas of the choroid and ciliary body. Int Ophthalmol Clin 1962;2:387-402.

5. Jensen OA. Malignant melanomas of the uvea in Denmark, 1943-1952: a clinical, histopathological, and prognostic study. Acta Ophthalmol (Suppl) 1963;75:141-89.

6. McLean IW, Foster WD, Zimmerman LE. Prognostic factors in small malignant melanomas of choroid and ciliary body. Arch Ophthalmol 1977;95:48-58.

7. Raivio I. Uveal melanomas in Finland: an epidemiological, clinical, histological, and prognostic study. Acta Ophthalmol (Suppl) 1977;133:5-64.

8. Shammas HF, Blodi FC. Prognostic factors in choroidal and ciliary body melanomas. Arch Ophthalmol 1977;95:63-9.

9. McLean IW, Foster WD, Zimmerman LE. Uveal melanoma: location, size, cell type, and enucleation as risk factors in metastasis. Hum Pathol 1982;13:123-32.

10. McLean IW, Foster WD, Zimmerman LE, Gamel JW. Modifications of Callender's classification of uveal melanoma at the Armed Forces Institute of Pathology. Am J Ophthalmol 1983;96:502-9.

11. Gamel JW, McCurdy JB, McLean IW. A comparison of prognostic covariates for uveal melanoma. Invest Ophthalmol Vis Sci 1992;33:1919-22.

12. Gamel JW, McLean IW, Foster WD, Zimmerman LE. Uveal melanomas: correlation of cytologic features with prognosis. Cancer 1978;41:1897-901.

13. Gamel JW, McLean IW, Greenberg RA, Zimmerman LE, Lichtenstein SJ. Computerized histologic assessment of malignant potential: a method for determining the prognosis of uveal melanomas. Hum Pathol 1982;13:893-7.

14. McCurdy J, Gamel J, McLean I. A simple, efficient, and reproducible method for estimating the malignant potential of uveal melanoma from H\&E slides. Pathol Res Pract 1991;187:1025-7.

15. Bissell MJ, Hall HG, Parry G. How does the extracellular matrix direct gene expression? Theor Biol 1982;99:31-68.

16. Madri JA, Basson MD. Extracellular matrix-cell interactions: dynamic modulators of cell, tissue and organism structure and function. Lab Invest 1992; 66:519-21.

17. Iozzo RV. Tumor stroma as a regulator of neoplastic behavior: agonostic and antagonistic elements embedded in the same connective tissue. Lab Invest 1995;73:157-60.

18. Vernon RB, Sage EH. Between molecules and morphology: extracellular matrix and creation of vascular form. Am J Pathol 1995;147:873-83.

19. Folkman J. Tumor angiogenesis. Adv Cancer Res 1985;43:175-203.

20. Folkman J. Seminars in medicine of the Beth Israel Hospital, Boston: clinical applications of research on angiogenesis. N Engl J Med 1995;333:1757-63.

21. Weidner N, Semple JP, Welch WR, Folkman J. Tumor angiogenesis and metastasis: correlation in invasive breast carcinoma. N Engl J Med 1991; 324:1-8.

22. Srivastava A, Laidler P, Hughes LE, Woodcock JP, Shedden EJ. Neovascularization in human cutaneous melanoma: a quantitative morphological and Doppler ultrasound study. Eur J Clin Oncol 1986;22:1205-9.

23. Fallowfield ME, Cook MG. Lymphatics in primary cutaneous melanoma. Am J Surg Pathol 1990;14: $370-4$.

24. Carnochan P, Briggs JC, Westbury G, Davies AJS. The vascularity of cutaneous melanoma: a quantitative histological study of lesions $0.85-1.25 \mathrm{~mm}$ in thickness. Br J Cancer 1991;64:102-7.

25. Macchiarini P, Fontanini G, Hardin MJ, Squartini F, Angeletti CA. Relation of neovascularisation to metastasis of non-small-cell lung cancer. Lancet 1992:340:145-6.

26. Wakui S, Furusato M, Itoh T, Sasaki H, Akiyama A, Kinoshita I, Asano K, Tokuda T, Aizawa S, Ushigome $\mathrm{S}$. Tumour angiogenesis in prostatic carcinoma with and without bone marrow metastasis: a morphometric study. J Pathol 1992;168:257-62.

27. Brawer MK, Deering RE, Brown M, Preston SD, Bigler SA. Predictors of pathologic stage in prostatic carcinoma. Cancer 1993;73:678-87.

28. Lipponen PK. The prognostic value of basement membrane morphology, tumour histology and morphometry in superficial bladder cancer. J Cancer Res Clin Oncol 1993;119:295-300.

29. Dickinson AJ, Fox SB, Persad RA, Hollyer J, Sibley GNA, Harris AL. Quantification of angiogenesis as an independent predictor of prognosis in invasive bladder carcinoma. Br J Urol 1994;74:762-6.

30. Bochner BH, Cote RJ, Weidner N, Groshen S, Chen SC, Skinner DG, Nichols PW. Angiogenesis in bladder cancer: relationship between microvessel density and tumor prognosis. J Natl Cancer Inst 1995;87:1603-12.

31. Roychowdhury DF, Tseng A, Fu KK, Windberg V, Weidner N. New prognostic factors in nasopharyngeal carcinoma: tumor angiogenesis and C-erbB2 expression. Cancer 1996;77:1419-26.

32. Leon SP, Folkerth RD, Black PM. Microvessel density is a prognostic indicator for patients with astroglial brain tumors. Cancer 1996;77:362-72.

33. Weidner $\mathbf{N}$. Intratumor microvessel density as a prognostic factor in cancer. Am $J$ Pathol 1995;147:9-19.

34. Lindmark G, Gerdin B, Sundberg C, Pahlman L, Bergstrom R, Glimelius B. Prognostic significance of the microvascular count in colorectal cancer. J Clin Oncol 1996;14:461-6. 
35. Busam KJ, Berwick M, Blessing K, Fandrey K, Kang $\mathrm{S}$, Karaoli $\mathrm{T}$, et al. Tumor vascularity is not a prognostic factor for malignant melanoma of the skin. Am J Pathol 1995;147:1049-56.

36. Page DL, Jensen RA. Angiogenesis in human breast carcinoma: what is the question? Hum Pathol 1995;26:1173-4.

37. Costello P, McCann A, Carney DN, Dervan PA. Prognostic significance of microvessel density in lymph node negative breast carcinoma. Hum Pathol 1995;26:1181-4.

38. Goulding H, Rashid NFAR, Robertson JF, Bell JA, Elston CW, Blamey RW, Ellis IO. Assessment of angiogenesis in breast carcinoma: an important factor in prognosis? Hum Pathol 1995;26:1196-200.

39. Ettinger L, Doljanski F. On the generation of form by the continuous interactions between cells and their extracellular matrix. Biol Rev Camb Philos Soc 1992;67:459-89.

40. Folberg R, Pe'er J, Gruman LM, Woolson RF, Jeng $\mathrm{G}$, Montague PR, et al. The morphologic characteristics of tumor blood vessels as a marker of tumor progression in primary human uveal melanoma: a matched case-control study. Hum Pathol 1992; 23:1298-305.

41. Folberg R, Rummelt V, Parys-Van Ginderdeuren R, Hwang T, Woolson RF, Pe'er J, Gruman LM. The prognostic value of tumor blood vessel morphology in primary uveal melanoma. Ophthalmology 1993;100: 1389-98.

42. Sakamoto T, Sakamoto H, Murphy TL, Spee C, Soriano $\mathrm{D}$, Ishibashi $\mathrm{T}$, et al. Vessel formation by choroidal endothelial cells in vitro is modulated by retinal pigment epithelial cells. Arch Ophthalmol 1995;113:512-20.

43. Elder DE, Murphy GF. Melanocytic tumors of the skin. Washington, DC: Armed Forces Institute of Pathology, 1991.

44. Gass JDM. Problems in the differential diagnosis of choroidal nevi and malignant melanomas: the XXXIII Edward Jackson Memorial Lecture. Am J Ophthalmol 1977;83:299-323.

45. Folberg R. Tumor progression in ocular melanomas. J Invest Dermatol 1993;100:326-31S.

46. Naumann G, Yanoff M, Zimmerman LE. Histogenesis of malignant melanomas of the uvea. I. Histopathologic characteristics of nevi of the choroid and ciliary body. Arch Ophthalmol 1996;76:784-96.

47. Naumann G. Pigmentierte Naevi der Aderhaut und des Ciliarkörpers. Adv Ophthalmol 1970;23:187-272.

48. Rummelt V, Folberg R, Rummelt C, Gruman LM, Hwang $\mathrm{T}$, Woolson $\mathrm{RF}$, et al. Microcirculation architecture of melanocytic nevi and malignant melanomas of the ciliary body and choroid: a comparative histopathologic and ultrastructural study. Ophthalmology 1994;101:718-27.

49. Rubin P, Casarett G. Microcirculation of tumors. I. Anatomy, function, and necrosis. Clin Radiol 1966; 17:220-9.

50. Eddy HA, Casarett GW. Development of the vascular system in the hamster malignant neurilemmoma. Microvasc Res 1973;6:63-82.

51. Less JR, Skalak TC, Sevick EM, Jain RK. Microvascular architecture in a mammary carcinoma: branching patterns and vessel dimensions. Cancer Res 1991;51:265-73.

52. Gaehtgens P. Why networks? Int J Microcirc Clin Exp 1992;11:123-32.
53. Gaudin PB, Rosai J. Florid vascular proliferation associated with neural and neuroendocrine neoplasms: a diagnostic clue and potential pitfall. Am J Surg Pathol 1995;19:642-52.

54. Groom AC, Ellis CG, Wrigley SJ, Potter RF. Capillary network morphology and capillary flow. Int J Microcirc Clin Exp 1995;15:223-30.

55. Skinner SA, Frydman GM, O'Brien PE. Microvascular structure of benign and malignant tumors of the colon in humans. Dig Dis Sci 1995;40:373-84.

56. Wilkins BS, Jones DB. Vascular networks within the stroma of human long-term bone marrow cultures. J Pathol 1995;177:295-301.

57. Brooks JJ, Disorders of soft tissue. In: Sternberg SS, editor. Diagnostic surgical pathology. 2nd ed. New York: Raven Press, 1996:147-229.

58. Rummelt V, Gardner LM, Folberg R, Beck S, Knosp $\mathrm{B}$, Moninger TO, Moore KC. Three-dimensional relationships between tumor cells and microcirculation using double cyanine-immunolabeling, laser scanning confocal microscopy and computer-assisted reconstruction: an alternative to cast corrosion preparations. J Histochem Cytochem 1994;42:681-6.

59. Gragoudas ES, Goitein M, Verhey L, Muzenreider J, Suit HD, Koehler A. A Proton beam irradiation: an alternative to enucleation for intraocular melanomas. Ophthalmology 1980;87:571-81.

60. Zinn KM, Stein/Pokorny K, Jakobiec FA, Friedman AH, Gragoudas ES, Ritch R. Proton-beam irradiated epithelial cell melanoma of the ciliary body. Ophthalmology 1981;88:1315-21.

61. Seddon JM, Gragoudas ES, Albert DM. Ciliary body and choroidal melanomas treated by proton beam irradiation: histopathologic study of eyes. Arch Ophthalmol 1983;101:1402-8.

62. Messmer E, Bornfeld N, Foerster M, Schilling H, Wessing A. Histopathologic findings in eyes treated with a ruthenium plaque for uveal melanoma. Graefes Arch Clin Exp Ophthalmol 1992;230:391-6.

63. Saornil MA, Egan KM, Gragoudas ES, Seddon JM, Walsh SM, Albert DM. Histopathology of proton beam-irradiated vs enucleated uveal melanomas. Arch Ophthalmol 1992;110:1112-8.

64. Dvorak HF, Nagy JA, Dvorak JT, Dvorak AM. Identification and characterization of the blood vessels of solid tumors that are leaky to circulating macromolecules. Am J Pathol 1988;133:95-109.

65. Sallet G, Amoaku WMK, Lafaut BA, Brabant P, Delaey JJ. Indocyanine green angiography of choroidal tumors. Graefes Arch Clin Exp Ophthalmol 1995;233:677-89.

66. Jain RK. Delivery of novel therapeutic agents in tumors: physiological barriers and strategies. J Natl Cancer Inst 1989;81:570-6.

67. Foss AJE, Alexander RA, Jeffries LW, Hungerford JL, Harris AL, Lightman S. Microvessel count predicts survival in uveal melanoma. Cancer Res 1996;56:2900-3.

68. Ruck P, Xiao JC, Kaiserling E. Immunoreactivity of sinusoids in hepatocellular carcinoma: an immunohistochemical study using lectin UEA-1 and antibodies against endothelial markers, including CD34. Arch Pathol Lab Med 1995;119:173-8.

69. Russell Jones R, Orchard G, Zelger B, Wilson Jones E. Immunostaining for CD31 and CD34 in Kaposi sarcoma. J Clin Pathol 1995;48:1011-6.

70. Mooy C, Vissers K, Luyten G, Mulder A, Stijnen T, Dejong P, Bosman F. DNA flow cytometry in uveal 
melanoma: the effect of pre-enucleation irradiation. Br J Ophthalmol 1995;79:174-7.

71. Huntington A, Haugan P, Gamel J, McLean I. A simple cytologic method for predicting the malignant potential of intraocular melanoma. Pathol Res Pract 1989;185:631-4.

72. Pe'er J, Rummelt V, Mawn L, Hwang T, Woolson RF, Folberg R. Mean of the ten largest nucleoli, microcirculation architecture, and prognosis of ciliochoroidal melanomas. Ophthalmology 1994;101:1227-35.

73. Coleman K, Baak JPA, van Diest PJ, Mullaney J. Prognostic value of morphometric features and the Callender classification in uveal melanomas. Ophthalmology 1996;103:1634-41.

74. Daniels KJ, Boldt HC, Martin JA, Gardner LM, Meyer M, Folberg R. Expression of type VI collagen in uveal melanoma: role in pattern formation and tumor progression. Lab Invest 1996;75:55-66.

75. McDevitt CA, Marcelino J, Tucker L. Interactions of intact type VI collagen with hyaluronan. FEBS Lett 1991;294:167-70.

76. Kielty CM, Whittaker SP, Grant ME, Shuttleworth CA. Type VI collagen forms a structural association with hyaluronan in vivo. Biochem Soc Trans 1991;19:384S.

77. Sage EH, Vernon RB. Regulation of angiogenesis by extracellular matrix: the growth and the glue. J Hypertens 1994;12:S145-52.

78. Zhang LQ, Laato M, Muona P, Kalimo H, Peltonen J. Normal and hypertrophic scars: quantification and localization of messenger RNAs for type I, III and VI collagens. Br J Dermatol 1994;130:453-9.

79. Denis C, Baruch D, Kielty CM, Ajzenberg N, Christophe E, Meyer D. Localization of von Willebrand factor binding domains to endothelial extracellular matrix and to type VI collagen. Arterioscler Thromb 1993;13:398-406.

80. Rand JH, Wu XX, Potter BJ, Uson RR, Gordon RE. Co-localization of von Willebrand factor and type VI collagen in human subendothelium. Am J Pathol 1993;142:843-50.

81. Hitraya EG, Tan EML, Rudnicka L, Jimenez SA. Expression of extracellular matrix genes in adult human dermal microvascular endothelial cells and their regulation by heparin and endothelial cell mitogens. Lab Invest 1995;73:393-402.

82. Marshall GE, Konstas AGP, Reid GG, Edwards JG, Lee WR. Collagens in the aged human macula. Graefes Arch Clin Exp Ophthalmol 1994;232:133-40.

83. Montesano R. Regulation of angiogenesis in vitro. Eur J Clin Invest 1992;22:504-15.

84. Seddon JM, Albert DM, Lavin PT, Robinson N. A prognostic factor study of disease-free interval and survival following enucleation for uveal melanoma. Arch Ophthalmol 1983;101:1894-9.

85. Rummelt V, Folberg R, Woolson RF, Hwang T, Pe'er J. Relation between the microcirculation architecture and the aggressive behavior of ciliary body melanomas. Ophthalmology 1995;102:844-51.

86. Speicher MR, Prescher G, du Manoir S, Jauch A, Horsthemke B, Bornfeld N, et al. Chromosomal gains and losses in uveal melanomas detected by comparative genomic hybridization. Cancer Res 1994;54: 3817-23.

87. Prescher G, Bornfeld N, Horsthemke B, Becher R. Chromosomal aberrations defining uveal melanoma of poor prognosis. Lancet 1992;339:691-2.

88. Augsburger JJ, Shields JA, Folberg R, Lang WR, O'Hara BJ, Claricci JD. Fine needle aspiration biopsy in the diagnosis of intraocular cancer cytologic-histologic correlations. Ophthalmology 1985;92:39-49.

89. Folberg R, Augsburger JJ, Gamel JW, Shields JA, Lang WR. Fine-needle aspirates of uveal melanomas and prognosis. Am J Ophthalmol 1985;100:654-7.

90. Char DH, Kroll SM, Stoloff A, Kaleta-Michaels S, Crawford JB, Miller TR et al. Cytomorphometry of uveal melanoma: comparison of fine needle aspiration biopsy samples with histologic sections. Anal Quant Cytol Histol 1991;13:293-9.

91. Bartsch D, Weinreb RN, Zinser G. Freeman WR. Confocal scanning infrared laser ophthalmoscopy for indocyanine green angiography. Am J Ophthalmol 1995;120:642-51.

92. Coleman DJ, Lizzi FL, Silverman RH, Rondeau MJ, Smith MD, Torpey JH. Acoustic biopsy as a means for characterization of intraocular tumors. In: Henkind P, editor. Acta XXIV International Congress of Ophthalmology. Philadelphia: JB Lippincott. 1982: $115-8$.

93. Schneider U, Gelisken F, Inhoffen W, Kreissig I. Indocyanine-green videoangiography of malignant melanomas of the choroid using the scanning laser ophthalmoscope. Ger J Ophthalmol 1996;5:6-11.

94. Coleman DJ, Silverman RH, Rondeau MJ, Lizzi FL, McLean IW, Jakobiec FA. Correlations of acoustic tissue typing of malignant melanoma and histopathologic features as a predictor of death. Am J Ophthalmol 1990;110:380-8.

95. Coleman DJ, Silverman RH, Rondeau MJ, Coleman JA, Rosberger D, Ellsworth RM, Lizzi FL. Ultrasonic tissue characterization of uveal melanoma and prediction of patient survival after enucleation and brachytherapy. Am J Ophthalmol 1991;112:682-8.

96. Feleppa EJ, Lizzi FL, Coleman DJ, Yaremko MM. Diagnostic spectrum analysis in ophthalmology: a physical perspective. Ultrasound Med Biol 1986;12:623-31.

97. Coleman DJ, Rondeau MJ, Silverman RH, Folberg R, Rummelt V, Woods SM, Lizzi FL. Correlation of microcirculation architecture with ultrasound parameters of uveal melanoma. Eur J Ophthalmol 1995;5:96-106.

98. MacNeil S, Wagner M, Kirkham PR, Blankson EA, Lennard MS, Goodall T, Rennie IG. Inhibition of melanoma cell matrix interaction by tamoxifen. Melanoma Res 1993;3:67-74.

99. MacNeil S, Wagner M, Rennie IG. Tamoxifen inhibition of ocular melanoma cell attachments to matrix proteins. Pigment Cell Res 1994;7:222-6.

100. MacNeil S, Wagner M, Rennie IG. Investigation of the role of signal transduction in attachment of ocular melanoma cells to matrix proteins: inhibition of attachment by calmodulin antagonists including tamoxifen. Clin Exp Med 1994;12:375-84.

101. Hilmas DE, Gillette EL. Morphometric analyses of the microvasculature of tumors during growth and after x-irradiation. Cancer 1974;33:103-10.

102. Falk P. Differences in vascular pattern between the spontaneous and the transplanted $\mathrm{C} 3 \mathrm{H}$ mouse mammary carcinoma. Eur J Cancer Clin Oncol 1982; 18:155-65.

103. Klaus H, Lommatzsch PK, Fuchs U. Histopathology studies in human malignant melanomas of the choroid after unsuccessful treatment with ${ }^{106} \mathrm{Ru} /{ }^{106} \mathrm{Rh}$ ophthalmic applicators. Graefes Arch Clin Exp Ophthalmol 1991;229:480-6. 
104. Finger PT. Microwave plaque thermodiotherapy for choroidal melanoma. $\mathrm{Br} \mathrm{J}$ Ophthalmol 1992;76: 358-64.

105. Storm FK, Harrison WH, Eliott RS, Hatzitheofilou C, Morton DL. Human hyperthermic therapy: relation between tumor type and capacity to induce hyperthermia by radiofrequency. Am J Surg 1979;138:170-4.

106. Coleman DJ, Silverman RH, Iwamoto T, Lizzi FL, Rondeau MJ, Driller J, et al. Histopathologic effects of ultrasonically induced hyperthermia in intraocular malignant melanoma. Ophthalmology 1988;95:970-81.

107. Endrich B, Hammersen F, Messmer K. Hyperthermia-induced changes in tumor microcirculation. Recent Results Cancer Res 1988;107:44-59.

108. Munzenrider JE, Gragoudas ES, Seddon JM, Sisterson $\mathrm{J}$, McNulty $\mathrm{P}$, Birnbaum $\mathrm{S}$, et al. Conservative treatment of uveal melanoma: probability of eye retention after proton treatment. Int J. Radiat Oncol Phys 1988;15:553-8.
109. Oosterhuis JA, Journeedekorver HG, Kakebeekekemme HM, Bleeker JC. Transpupillary thermotherapy in choroidal melamomas. Arch Ophthalmol 1995;113:315-21.

110. Steeves RA, Tompkins DT, Nash RN, Blair JR, Gentry LL, Paliwal BR, et al. Thermoradiotherapy of intraocular tumors in an animal model: concurrent vs sequential brachytherapy and ferromagnetic hyperthermia. Int J Radiat Oncol Biol Phys 1995; 33:659-62.

111. Zolzer F, Streffer C. Cell cycle-dependent expression of Ki-67 antigen in human melanoma cells subjected to irradiation and/or hyperthermia. Radiat Res 1995; 143:98-101.

112. Harris AL, Zhang HT, Moghaddam A, Fox S, Scott P, Pattison $\mathrm{A}$, et al. Breast cancer angiogenesis: new approaches to therapy via antiangiogenesis, hypoxic activated drugs, and vascular targeting. Breast Cancer Res Treat 1996;38:97-108. 